\title{
The popliteal surface axis may define hip anteversion
}

\author{
Alp Akman, MD'1D, Ahmet Fahir Demirkan, $\mathrm{MD}^{1} \mathbb{D}$, Nuran Sabir Akkoyunlu, MD²], \\ Ali Çağdaş Yörükoğlu, MD'1D \\ ${ }^{1}$ Department of Orthopedics and Traumatology, Pamukkale University Faculty of Medicine, Denizli, Turkey \\ 2Department of Radiology, Medical Faculty of Pamukkale University, Denizli, Turkey
}

For the distal reference axis in femoral anteversion determination, the posterior condylar axis (PCA) which uses the most posterior points of the medial and lateral epicondyles is mostly used. ${ }^{[1]}$ Alternatively, we may use a trans-epicondylar axis (TEA) which is defined as a line between the most prominent points of medial and lateral epicondyles. ${ }^{[2]}$ However, it has been known that bone and cartilage loss and/or the osteophyte formation in the osteoarthritic knee with aging affects both PCA and TEA. ${ }^{[2,3]}$ Furthermore, the determination of anteversion is very challenging in case of destruction of one or two condyle due to mass, infection or fracture. In these conditions, both PCA and TEA become unreliable. To eliminate these concerns, a new distal reference axis has been proposed. We hypothesized that a new distal reference axis based on popliteal surface may be used as an alternative reference axis for hip anteversion determination. The femur in its distal third, the shaft has a flat triangular posterior surface (i.e., popliteal surface) between the medial and lateral supracondylar lines, which is continuous above with the corresponding edges of the linea aspera. ${ }^{[4]}$ The new axis has been defined on this surface as a transverse line between supracondylar ridges and four centimeters proximal to the intercondylar line

Received: March 05, 2019

Accepted: October 24, 2019

Published online: March 02, 2020

Correspondence: Ahmet Fahir Demirkan, MD. Pamukkale

Üniversitesi Tıp Fakültesi Ortopedi ve Travmatoloji Anabilim Dalı, 20160 Pamukkale, Denizli, Türkiye.

E-mail: fahirdemirkan@yahoo.com

Dol: $10.5606 /$ ehc. 2020.65259

Citation: Akman A, Demirkan AF, Sabir Akkoyunlu N, Yörükoğlu AÇ. The popliteal surface axis may define hip anteversion. Jt Dis Relat Surg 2020;31(1):28-33.

\section{ABSTRACT}

Objectives: This study aims to investigate the usability and reliability of our new axis in a three-dimensional modelling work and demonstrate if it is a reproducible method for anteversion measurement that sufficiently correlates with other computed tomography (CT)-derived gold standards including transepicondylar axis (TEA) and posterior condylar axis (PCA).

Patients and methods: Three-dimensional solid models were derived from left femoral CT data of 100 participants (50 males, 50 females; mean age 57 years; range, 21 to 86). The newly proposed popliteal surface axis (PSA) was compared with TEA and PCA in terms of anteversion measurement on these solid models.

Results: Popliteal surface axis was found as a reproducible reference axis in our study as it could be measured in $99 \%$ of our sample. The mean value of PSA based anteversion was (-) $1.8^{\circ}$ which was $10.7^{\circ}$ and $4.4^{\circ}$ for PCA and TEA, respectively. Popliteal surface axis was perfectly correlated with PCA and TEA for anteversion measurements ( $\mathrm{p}<0.001, \mathrm{r}=0.92$ for both).

Conclusion: Our findings suggest that the newly defined PSA may be used as an alternative method for determination of anteversion.

Keywords: Anteversion, femur, human, popliteal surface axis, posterior condylar axis, trans-epicondylar axis, three-dimensional modelling.

and we call it as popliteal surface axis (PSA). In this study, we aimed to investigate the usability and reliability of our new axis in a three-dimensional (3D) modelling work and demonstrate if it is a reproducible method for anteversion measurement that sufficiently correlates with other computed tomography (CT)derived gold standards including TEA and PCA. ${ }^{[5]}$

\section{PATIENTS AND METHODS}

This study was conducted at Pamukkale University Faculty of Medicine Hospital between July 2015 to December 2015. We designed an analytical and observational cross-sectional survey study regarding anteversion measurement using CT-derived values. 
The left femoral CT data of 100 participants (50 males, 50 females; mean age 57 years; range, 21 to 86), which were taken from whole body scans during positron emission tomography examination for another reason, were used. Inclusion criteria were a standard protocol used while taking CT scans (12 kV, $195 \mathrm{mAs})$, the whole femur scan including adjacent joints being in a single field of vision, a scanning resolution of $512 \times 512$ pixels, the scanning being sequential and in a standard slice thickness of $5 \mathrm{~mm}$ thick and $5 \mathrm{~mm}$ apart, and age more than 18 years. Exclusion criteria were excessive osteoporosis on whole bone models as a result of aging or previously taken chemotherapy or radiotherapy etc., previous operations or a present deformity or metallic objects/implants on the lower extremity and/or pelvis, any involvement of tumoral lesion and/or metastatic lesion in lower extremity and/or pelvis. The study protocol was approved by the Pamukkale University, Faculty of Medicine Ethics Committee (Date: 10/07/2015; No: 60116787-020/41032). A written informed consent was obtained from each patient. The study was conducted in accordance with the principles of the Declaration of Helsinki.

By using CT data, left femur models were created using Mimics version 10 (Materialise, Leuven, Belgium) program. The minimum threshold was set to 200 Hounsfield units for bone determination. A mask for each of the left femur was created and edited to effectively separate. 3D solid models were then generated from these to measure intended angle values. For measurements: A PCA was established between the medial and the lateral condyles at their most posterior points as described by Murphy et al. ${ }^{[1]}$ (red line in Figures 1 and 2) A coronal femoral plane
(CFP) was established between PCA and the most posterior point of the greater trochanter (red point in Figures 1 and 2) as defined by Kingsley and Olmsted. ${ }^{[6]}$ Femoral neck anteversion (FNA) axis (blue line in Figures 1 and 2) was between the center of the femoral head (magenta point in Figures 1 and 2) and the center-point of the narrowest segment of the femoral neck (turquoise point in Figures 1 and 2) as defined by Reikerås et al. ${ }^{[7]}$ while the environment was 3D. The center of the femoral head was found by the center of the best fitting sphere (grey sphere in Figure 1). A TEA (orange line in Figures 1 and 2) was defined between the most prominent points of the medial and lateral epicondyles as defined by Yoshioka et al. ${ }^{[2]}$ The PSA was defined as the transverse axis on the flat popliteal surface between medial and lateral supracondylar ridges $4 \mathrm{~cm}$ proximal to the intercondylar line (green line in Figures 1 and 2). Some participants' small rough area for the attachment of plantaris muscle was placed in popliteal surface region and we simply ignored it. Additionally, a sagittal femoral plane perpendicular to the CFP was established as the plane that passed through the points as described by Sugano et al. ${ }^{[8]}$ which were the center of distal femur (dark grey line in Figures 1 and 2) and center-point of section just below the lesser trochanter (dark grey point in Figures 1 and 2). At the final step, at the cranio-caudal view, the processed femur model was rotated until the CFP and SBP became lines. If these two planes were seen as cross-hair lines on the screen, then it meant that the femur was aligned perpendicular to them (Figure 2). Afterwards, the angles between FNA axis and PCA (PCAA), and TEA (TEAA), and PSA (PSAA) were measured (Figure 3).
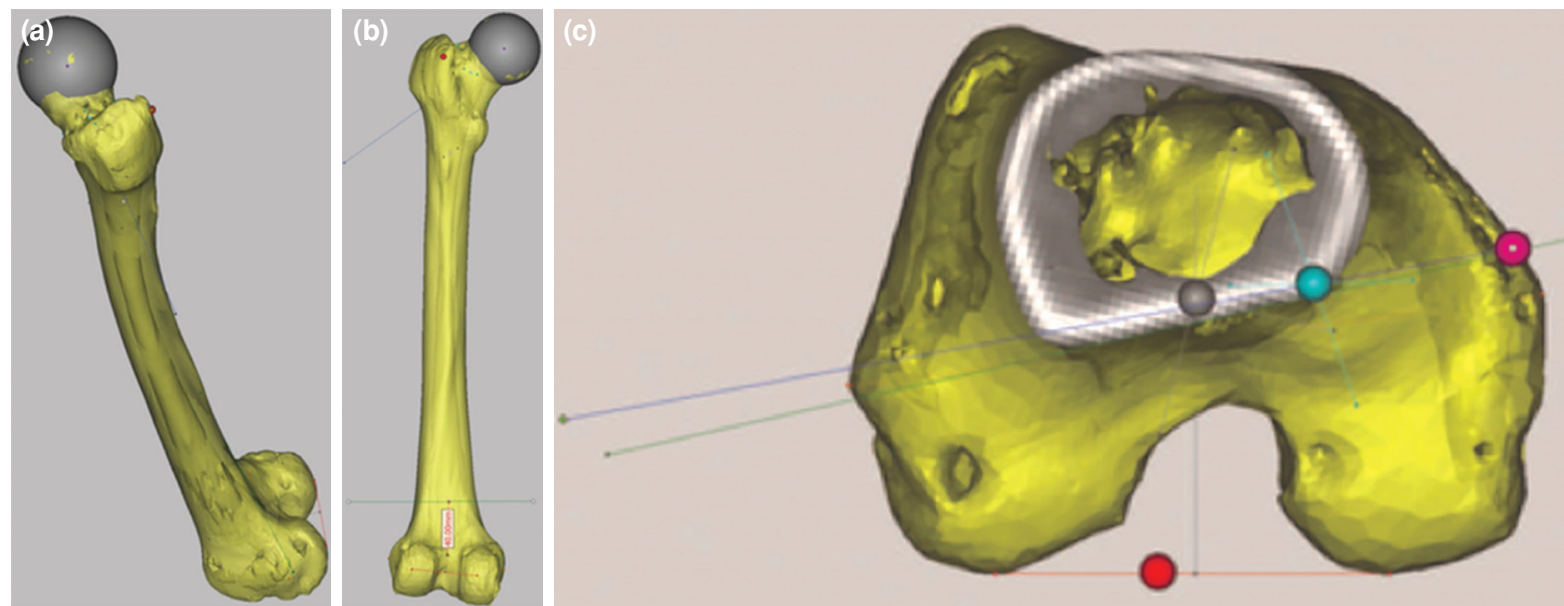

FIGURE 1. Establishment of points, axes and planes on a three-dimensional (3D) model for angle measurements in distal femur; (a) in 3D space, (b) in posterior-anterior view and (c) in cranio-caudal view. 


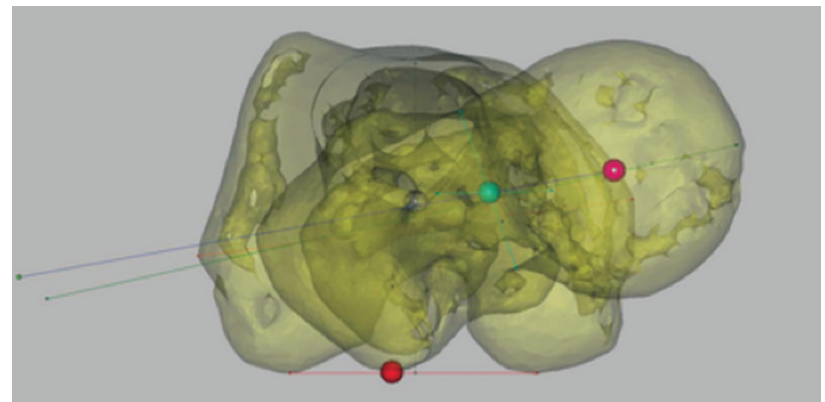

FIGURE 2. Established references with three-dimensional bone model in cranio-caudal view.

\section{Statistical analysis}

We used the PASW version 18.0 software (SPSS Inc., Chicago, IL, USA) for statistical analysis. Independent samples t-test was used for comparison of the dichotomous data. Test correlations were performed with Pearson correlation method. The measurements of two authors that were conducted six months apart were used for intra- and interobserver consistency analysis. Intra-observer consistency analysis was established with intraclass correlation coefficient whereas inter-observer with Kendall's tau. We did not perform any a priori power analysis. A $p<0.05$ was considered as statistically significant.

\section{RESULTS}

The mean age of the participants was 60 years in males (range, 23 to 84 years) and 54 years in females (range, 21 to 86 years). We were unable to detect the PSA in only one participant as there were two surfaces on the popliteal surface and this participant was subsequently excluded from the study. Therefore, the establishment rate of PSA was 99\%.

Intra-observer reliabilities were $0.95 \quad(95 \%$ confidence interval [CI]: 0.93 to 0.97 ) for the first observer and 0.94 (95\% CI: 0.92 to 0.96 ) for the second.

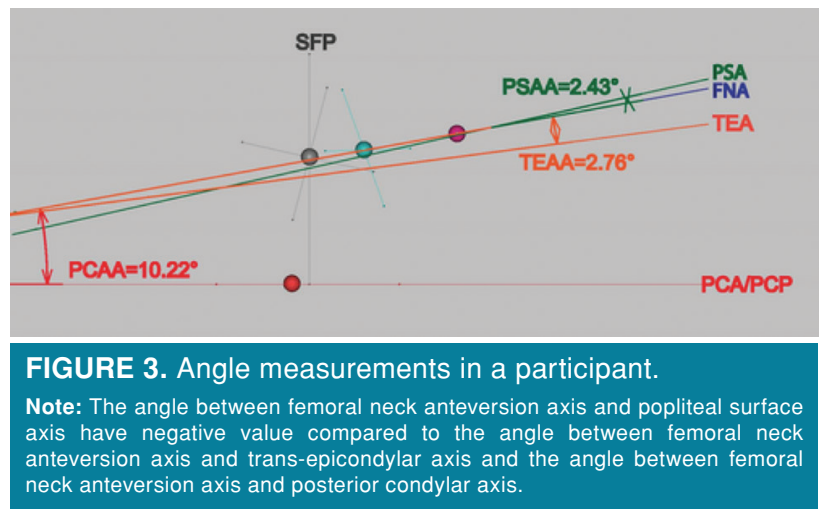

Inter-observer reliabilities were 0.82 (95\% CI: 0.76 to 0.86 ) for the first measurements and 0.84 ( $95 \%$ CI: 0.78 to 0.88 ) for the second ( $\mathrm{p}<0.001$ for all).

The mean values of PCAA, TEAA and PSAA were summarized in Table I. The mean PSAA had negative value of $(-) 1.8^{\circ}$ compared to TEAA $\left(4.4^{\circ}\right)$ and PSAA $\left(10.7^{\circ}\right)$. These values were not statistically different according to gender. Age did not affect these values either.

The angles between distal reference axes which were between PCA and TEA (PCA-TEA), between PCA and TEA (PCA-TEA) and between PCA and PSA (PCA-PSA) were summarized in Table II. For these values, the gender differences were not statistically significant. The PCA-TEA changed with age unlike PCA-PSA and TEA-PSA ( $\mathrm{p}=0.022)$.

The correlations of PCAA, TEAA and PSAA were summarized in Table III. All were perfectly correlated with each other: every $1^{\circ}$ change in PCAA resulted in $1^{\circ}$ change in TEAA and $0.9^{\circ}$ in PSAA (Figure 4).

\section{DISCUSSION}

The most important finding of the present study was that the newly defined PSA perfectly correlated with gold standards and may be a good alternative

\begin{tabular}{|c|c|c|c|c|c|c|c|}
\hline \multicolumn{8}{|c|}{ TABLE I } \\
\hline \multirow[b]{2}{*}{ Variable } & \multicolumn{2}{|c|}{ All $(n=99)$} & \multicolumn{2}{|c|}{ Males $(n=49)$} & \multicolumn{2}{|c|}{ Females $(n=50)$} & \multirow[b]{2}{*}{$p^{*}$} \\
\hline & Mean $\pm S D$ & Min-Max & Mean $\pm S D$ & Min-Max & Mean \pm SD & Min-Max & \\
\hline PCAA & $10.7 \pm 9.2$ & $-7.8-31.2$ & $9.4 \pm 8.5$ & $-7.0-28.8$ & $12.1 \pm 9.7$ & $-7.8-31.2$ & $0.141,0.179$ \\
\hline TEAA & $4.4 \pm 9.0$ & $-14.6-24.2$ & $3.2 \pm 7.9$ & $-14.6-21.1$ & $5.6 \pm 9.9$ & $-13.8-24.2$ & $0.189,0.361$ \\
\hline PSAA & $-1.8 \pm 9.3$ & $-24.1-16.9$ & $-3.0 \pm 8.6$ & $-24.1-15.3$ & $-0.6 \pm 9.9$ & $-23.9-16.9$ & $0.205,0.158$ \\
\hline
\end{tabular}




\begin{tabular}{|c|c|c|c|c|c|c|c|}
\hline \multirow[b]{3}{*}{ Variables } & \multicolumn{6}{|c|}{$\begin{array}{l}\text { TABLE II } \\
\text { leen distal reference axes }\end{array}$} & \multirow[b]{3}{*}{$p^{*}$} \\
\hline & \multicolumn{2}{|c|}{ All $(n=99)$} & \multicolumn{2}{|c|}{ Males $(n=49)$} & \multicolumn{2}{|c|}{ Females $(n=50)$} & \\
\hline & Mean $\pm S D$ & Min-Max & Mean $\pm S D$ & Min-Max & Mean $\pm S D$ & Min-Max & \\
\hline PCA-TEA (CTA) & $6.3 \pm 1.8$ & $2.4-10.2$ & $6.2 \pm 1.9$ & $2.4-10.1$ & $6.5 \pm 1.7$ & $2.8-10.2$ & $0.347,0.022^{* *}$ \\
\hline TEA-PSA & $6.2 \pm 3.7$ & $-3.9-18.6$ & $6.2 \pm 3.8$ & $-3.9)-18.6$ & $6.2 \pm 3.5$ & $-1.3)-14.7$ & $0.995,0.824$ \\
\hline PCA-PSA & $12.5 \pm 3.6$ & 3.2-23.6 & $12.3 \pm 4.1$ & $3.2-23.6$ & $12.7 \pm 3.2$ & $5.4-20.0$ & $0.637,0.181$ \\
\hline
\end{tabular}

SD: Standard deviation; Min: Minimum; Max: Maximum; PCA: Posterior condylar axis; TEA: Trans-epicondylar axis; CTA: Condylar twist angle; PSA: Popliteal surface axis; * Statistical significance among gender and age, respectively; ${ }^{\star \star}$ Accepted as statistically significant; All values are given in degrees.

\begin{tabular}{|c|c|c|c|}
\hline \multicolumn{4}{|c|}{$\begin{array}{c}\text { TABLE III } \\
\text { The correlations of PSAA, PCAA and TEAA }\end{array}$} \\
\hline Variables & All $(n=99)$ & Males $(n=49)$ & Females $(n=50)$ \\
\hline \multicolumn{4}{|c|}{ PSAA with PCAA } \\
\hline $\mathrm{p}$ & $<0.001^{*}$ & $<0.001^{*}$ & $<0.001^{*}$ \\
\hline$r$ & $=0.923$ & $=0.887$ & $=0.947$ \\
\hline \multicolumn{4}{|c|}{ PSAA with TEAA } \\
\hline$p$ & $<0.001^{*}$ & $<0.001^{*}$ & $<0.001^{*}$ \\
\hline$r$ & $=0.920$ & $=0.895$ & $=0.936$ \\
\hline \multicolumn{4}{|c|}{ PCAA with TEAA } \\
\hline$p$ & $<0.001^{*}$ & $<0.001^{*}$ & $<0.001^{*}$ \\
\hline$r$ & $=0.981$ & $=0.975$ & $=0.985$ \\
\hline $\begin{array}{l}\text { PSAA: Angle } \\
\text { anteversion } \\
\text { dylar axis; * }\end{array}$ & $\begin{array}{l}\text { and poplite } \\
\text { Angle betwe }\end{array}$ & $\begin{array}{l}\text { ce axis; PCAA: Ang } \\
\text { oral neck anteversio }\end{array}$ & $\begin{array}{l}\text { petween femoral neck } \\
\text { axis and trans-epicon }\end{array}$ \\
\hline
\end{tabular}

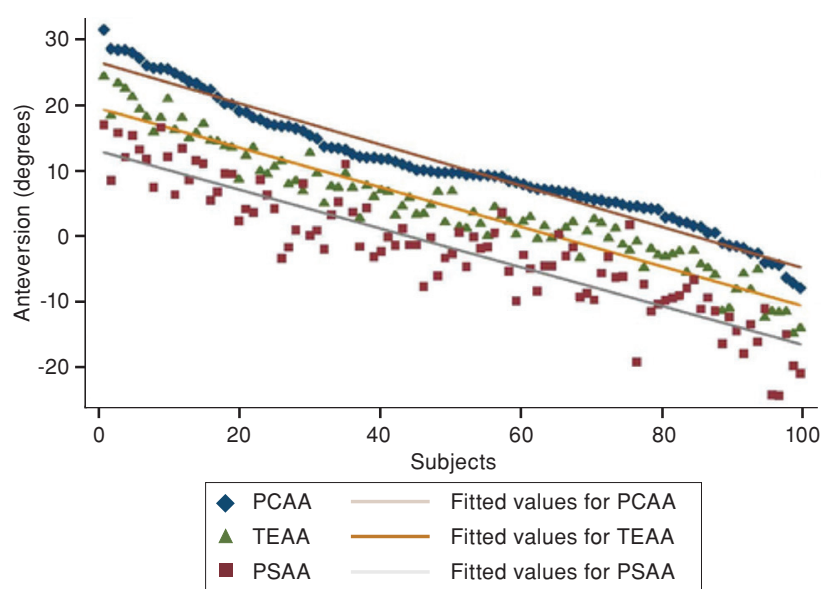

FIGURE 4. Relationship between angle values with different distal reference axes (Lines are showing linear predictions. Participants are in decreasing order according to angles between femoral neck anteversion axis and posterior condylar axis).

PCAA: Angle between femoral neck anteversion axis and posterior condylar axis; TEAA: Angle between femoral neck anteversion axis and transepicondylar axis; PSAA: Angle between femoral neck anteversion axis and popliteal surface axis. method for anteversion determination. Furthermore, the establishment rate of PSA was $99 \%$.

Posterior condylar axis-PSA had an average of $12.5^{\circ}$ in our study which was $6.2^{\circ}$ for TEA-PSA. PCA-TEA was affected from age unlike PCA-PSA and TEA-PSA. The effect of age on PCA-TEA may be attributed to bone and cartilage loss and/or the osteophyte formation in the osteoarthritic knee which increases with aging. ${ }^{[2,3]}$ In contrast, PSA related measurements were not affected as the PSA is a metaphysis-based reference axis.

Among previous studies on anteversion using PCA in which the race and/or the gender were taken into consideration, Reikerås et al. ${ }^{[9]}$ found an average version of $10.2^{\circ}$ in males and $10.7^{\circ}$ in females in 48 pairs of normal cadavers in Norwegians. They discovered no significant difference between genders. In a cadaveric study by Hoaglund and Low ${ }^{[10]}$ who compared Caucasians and Chinese, anteversion angle had an average of $7.1^{\circ}$ in males and $10.8^{\circ}$ in 
females among Caucasians which were $14.1^{\circ}$ and $16.8^{\circ}$, respectively, among Chinese. Koerner et al. ${ }^{[1]]}$ showed that the mean anteversion values of males were $7.9^{\circ}$ for Caucasians, $9.0^{\circ}$ for African Americans and $8.7^{\circ}$ for Hispanics in their CT study consisting 411 femurs. These values were $12.9^{\circ}, 8.2^{\circ}$ and $8.7^{\circ}$ for females, respectively. They detected no significant differences between genders across ethnicities. Moreover, Chantarapanich et al..$^{[12]}$ reported a value of $8.7^{\circ}$ for males and $10.8^{\circ}$ for females in their study of Thai people and found a statistical significance in gender differences. In a CT-derived study from Turkey, Akalin et al. ${ }^{[13]}$ found $9.3^{\circ}$ and gender difference was not reported. In our study, the mean anteversion value was $10.7^{\circ}$ which was $9.4^{\circ}$ for males and $12.1^{\circ}$ for females. Thus, the results of our study were similar to those of the previous studies.

Most of the literature assessing the rotational alignment of the distal femur in total knee arthroplasty use PSA-TEA which is also named as the condylar twist angle. ${ }^{[13-15]}$ For Caucasians: Arima et al. ${ }^{[14]}$ found a mean value of $5.7^{\circ}$ in $\mathrm{CT}$ measurements which was $4.4^{\circ}$ in cadaveric measurements. Mantas et al. ${ }^{[16]}$ reported a mean value of $4.9^{\circ}$ in their cadaveric study which was $4.4^{\circ}$ in males and $6.4^{\circ}$ in females. The gender difference was statistically different in their study. In contrast, Wright et al. ${ }^{[15]}$ reported $6.7^{\circ}$ in their CT-based 3D modelling studies similar to us (in 30 males and 30 females). The females and males had the same mean value in their study. For Asians: Yoshioka et al. ${ }^{[2]}$ reported a mean of $5^{\circ}$ in females and $6^{\circ}$ in males in their cadaveric study; however, the difference was not statistically significant. Sathappan et $a .^{[17]}$ reported a mean of $6.9^{\circ}$ without gender discrimination. Park et al. ${ }^{[18]}$ reported $6^{\circ}$ in nontibia vara group ( $94 \%$ females) in their magnetic resonance study. Our study showed a mean value of $6.3^{\circ}$ which is comparable with previous results again. Meanwhile, females had a mean value of $6.2^{\circ}$ which was $6.5^{\circ}$ for males and the difference was not statistically significant.

The main downside of our reference axis is that it is mainly available by $\mathrm{CT}$ and rarely noticed because of its anatomic location. Furthermore, the technical limitation of our study is the subjective nature of point selection for measurements of angles and its inherent error. The models were derived from $5 \mathrm{~mm}$ thick and $5 \mathrm{~mm}$ apart sequential $\mathrm{CT}$ data which reduce resolution.

In conclusion, our findings suggest that the newly defined distal reference axis in anteversion determination may be used as an alternative measurement. We believe that further research needs to be performed on this topic for clinical use and to reveal the importance of PSA.

\section{Declaration of conflicting interests}

The authors declared no conflicts of interest with respect to the authorship and/or publication of this article.

\section{Funding}

The authors received no financial support for the research and/or authorship of this article.

\section{REFERENCES}

1. Murphy SB, Simon SR, Kijewski PK, Wilkinson RH, Griscom NT. Femoral anteversion. J Bone Joint Surg [Am] 1987;69:1169-76.

2. Yoshioka Y, Siu D, Cooke TD. The anatomy and functional axes of the femur. J Bone Joint Surg [Am] 1987;69:873-80.

3. Griffin FM, Math K, Scuderi GR, Insall JN, Poilvache PL. Anatomy of the epicondyles of the distal femur: MRI analysis of normal knees. J Arthroplasty 2000;15:354-9.

4. Snell RS. The lower limb. In: Snell RS, editor. Clinical anatomy by regions. 8th ed. Philadelphia: Wolters Kluwer (Health)/Lippincott Williams \& Wilkins; 1990. p. 549-68.

5. Atik OŞ. Is there something new and interesting in my article? Eklem Hastalik Cerrahisi 2019;30:69.

6. Kingsley PC, Olmsted KL. A study to determine the angle of anteversion of the neck of the femur. J Bone Joint Surg [Am] 1948;30:745-51.

7. Reikerås O, Bjerkreim I, Kolbenstvedt A. Anteversion of the acetabulum and femoral neck in normals and in patients with osteoarthritis of the hip. Acta Orthop Scand 1983;54:18-23.

8. Sugano N, Noble PC, Kamaric E. A comparison of alternative methods of measuring femoral anteversion. J Comput Assist Tomogr 1998;22:610-4.

9. Reikerås $\mathrm{O}$, Høiseth A, Reigstad A, Fönstelien E. Femoral neck angles: a specimen study with special regard to bilateral differences. Acta Orthop Scand 1982;53:775-9.

10. Hoaglund FT, Low WD. Anatomy of the femoral neck and head, with comparative data from Caucasians and Hong Kong Chinese. Clin Orthop Relat Res 1980;152:10-6.

11. Koerner JD, Patel NM, Yoon RS, Sirkin MS, Reilly MC, Liporace FA. Femoral version of the general population: does "normal" vary by gender or ethnicity? J Orthop Trauma 2013;27:308-11.

12. Chantarapanich N, Rojanasthien $S$, Chernchujit B, Mahaisavariya B, Karunratanakul K, Chalermkarnnon P, et al. 3D CAD/reverse engineering technique for assessment of Thai morphology: Proximal femur and acetabulum. J Orthop Sci 2017;22:703-9.

13. Akalın Y, Ozçelik A, Köse N, Seber S. Rotational alignment of the lower extremity in adults: no relationship with osteoarthritis of the knee was proved. Eklem Hastalik Cerrahisi 2011;22:75-80.

14. Arima J, Whiteside LA, McCarthy DS, White SE. Femoral rotational alignment, based on the anteroposterior axis, in total knee arthroplasty in a valgus knee. A technical note. J Bone Joint Surg [Am] 1995;77:1331-4.

15. Wright SJ, Boymans TA, Grimm B, Miles AW, Kessler O. Strong correlation between the morphology of the proximal femur and the geometry of the distal femoral trochlea. Knee Surg Sports Traumatol Arthrosc 2014;22:2900-10. 
16. Mantas JP, Bloebaum RD, Skedros JG, Hofmann AA. Implications of reference axes used for rotational alignment of the femoral component in primary and revision knee arthroplasty. J Arthroplasty 1992;7:531-5.

17. Sathappan SS, Tan MW, Ginat D, Walsh MG, Schweitzer $\mathrm{ME}, \mathrm{Di}$ Cesare PE. Correlation between the distal anterior femoral cortical axis and femoral rotational alignment: an anatomic study. J Orthop Surg (Hong Kong) 2016;24:198-203.

18. Park IS, Ong A, Nam CH, Ahn NK, Ahn HS, Lee SC, et al. Transepicondylar axes for femoral component rotation might produce flexion asymmetry during total knee arthroplasty in knees with proximal tibia vara. Knee 2014;21:369-73. 